\title{
Outbreak investigations in the Western Pacific Region
}

\author{
Michelle McPherson ${ }^{a}$ and Ailan Lia
}

n this issue we introduce a new article type - the outbreak investigation report - with our theme Outbreak investigations in the Western Pacific Region. This new article type allows for concise reports on outbreak investigations and expands the role of the Western Pacific Surveillance and Response Journal (WPSAR) as a regional information-sharing platform, as per the Asia Pacific Strategy for Emerging Diseases (APSED $2010)^{1}$ in line with the International Health Regulation (2005). ${ }^{2}$ Timely sharing of outbreak investigations may be useful in informing public health action across the Region. We received 11 outbreak investigation report submissions and one original research of an outbreak investigation from six countries and areas within the World Health Organization's Western Pacific Region.

We also publish the first risk assessment article in this issue, which followed the World Health Organization's Rapid Risk Assessment of Acute Public Health Events. ${ }^{3}$ We look forward to publishing more risk assessments as their documentation becomes more routinely established.

To support the timely sharing of information within the Region, in this issue we trialled a rapid peer review process. We requested reviewers to complete their reviews within 48 hours of receipt. Several of the 22 reviewers completed these on the same day of the request, with an average review time of 2.3 days. The shortest time between submission and publication was 18 days, with the average being 44 days. Having this pool of supportive reviewers demonstrates the potential for future rapid publications, suggesting that WPSAR can be used as a regional centre for information sharing of surveillance and response articles during major public health events, rather than relying on journals from outside the Region. ${ }^{4}$

In this issue five foodborne or waterborne illness outbreaks are described. An outbreak of Vibrio parahemolyticus, detected through event-based surveillance, was linked to seafood served during a wedding in Cambodia. ${ }^{5}$ A Campylobacter outbreak associated with the known risk factor of chicken liver pâté in Australia emphasizes the ongoing need for food handler education on dealing with high-risk foods. ${ }^{6}$ Three outbreaks in China were associated with water sources - an Aeromonas hydrophila outbreak from vegetables washed in contaminated water, ${ }^{7}$ a hepatitis A outbreak linked to a school well in a rural area, ${ }^{8}$ and an outbreak of Escherichia coli linked to contaminated bottled water. ${ }^{9}$

There were five outbreaks of vaccine-preventable diseases. Two measles outbreaks, from Australia and Singapore, both occurred in unvaccinated persons and then subsequently spread to others within health care facilities, highlighting the role that such facilities can play in transmission of disease. ${ }^{10,11}$ Two mumps outbreaks are also described, one from China suggesting that a single dose of mumps-containing vaccine may not be effective in preventing outbreaks among schoolchildren; ${ }^{12}$ the other the first mumps outbreak since the introduction of the measles-mumps-rubella vaccine in Mongolia, although there were no cases in children eligible for vaccination, rather in the unvaccinated population. ${ }^{13}$ A pertussis outbreak from Papua New Guinea focuses on the difficulties in investigating outbreaks in remote locations, and the additional burden of vaccinating as an outbreak response incurs, compared to conducting routine vaccination programmes. ${ }^{14}$

A syphilis outbreak occurring in Mongolia among young persons highlights the high risk behaviours in this group and the need for contact tracing and targeted health promotion efforts. ${ }^{15} \mathrm{~A}$ cutaneous anthrax outbreak was reported from an area in China that has not had anthrax cases in decades. ${ }^{16}$ Eight of the 12 outbreaks reported in this issue were conducted by Field Epidemiology Training Programme (FETP) fellows, with a further two authored 
by graduates of FETP. This highlights the important role that FETP plays in the Region in both the investigation and reporting of these events.

The new outbreak investigation article type is now a permanent component of WPSAR, and we look forward to publishing more of these concise reports in the New Year.

On behalf of the Editorial team, we also thank all our peer reviewers for their contribution to WPSAR; a full list of reviewers is included in this issue.

\section{References:}

1. Asia Pacific Strategy for Emerging Disease (2010). Manila, World Health Organization Regional Office for the Western Pacific, 2011 (http://www.wpro.who.int/emerging_diseases/documents/docs/ ASPED_2010.pdf, accessed 28 August 2012).

2. International Health Regulation (2005), $2^{\text {nd }}$ edition. Geneva, World Health Organization, 2008 (http://whqlibdoc.who.int/ publications/2008/9789241580410_eng.pdf, accesssed 28 August 2012).

3. Rapid Risk Assessment of Acute Public Health Events. Geneva, World Health Organization, 2012 (http://whqlibdoc. who.int/hq/2012/WHO_HSE_GAR_ARO_2012.1_eng.pdf, accessed 28 August 2012).

4. Field E, Kasai T. Western Pacific Surveillance and Response: a journal to reflect the needs of our Region. Western Pacific Surveillance and Response Journal, 2010, 1:1-2. doi:10.5365/ wpsar.2010.1.1.007

5. Vandy S et al. Vibrio parahaemolyticus enteritis outbreak following a wedding banquet in a rural village - Kampong Speu, Cambodia, April 2012. Western Pacific Surveillance and Response Journal, 2012, 3(4):25-28. doi:10.5365/wpsar.2012.3.4.004

6. Parry A, Fearnley E, Denehy E. 'Surprise': Outbreak of Campylobacter infection associated with chicken liver pâté at a surprise birthday party, Adelaide, Australia, 2012. Western Pacific Surveillance and Response Journal, 2012, 3(4):16-19. doi:10.5365/wpsar.2012.3.4.011
7. Qian Z et al. A food-borne outbreak of Aeromonas hydrophila in a college, Xingyi City, Guizhou, China, 2012. Western Pacific Surveillance and Response Journal, 2012, 3(4). doi: $10.5365 / 2012.3 .4 .018$

8. $\mathrm{Xu} Y Q$ et al. An outbreak of viral hepatitis $A$ associated with possible contaminated school well in one middle school, Guangxi, China. Western Pacific Surveillance and Response Journal, 2012, 3(4):39-43. doi:10.5365/wpsar.2012.3.4.014

9. Wang $\mathrm{R}$ et al. An outbreak of acute gastroenteritis associated with contaminated bottled water in a university - Jiangxi, China, 2012. Western Pacific Surveillance and Response Journal, 2012, 3(4):44-47. doi:10.5365/wpsar.2012.3.4.009

10. Hope $\mathrm{K}$ et al. Measles transmission in health care waiting rooms: implications for public health response. Western Pacific Surveillance and Response Journal, 2012, 3(4):33-38. doi:10.5365/wpsar.2012.3.3.009

11. Low $C$ et al. Possible nosocomial transmission of measles in unvaccinated children in a Singapore public hospital. Western Pacific Surveillance and Response Journal, 2012, 3(4):7-11. doi:10.5365/wpsar.2012.3.4.008

12. Wang $M$ et al. Is single dose of routine mumps vaccine effective? A retrospective cohort study among children in a day-care center and a primary school in Guangdong province, China. Western Pacific Surveillance and Response Journal, 2012, 3(4):29-32. doi:10.5365/wpsar.2012.3.4.012

13. Jargalsaikhan $S$ et al. Mumps outbreak in Gurvantes soum, Omnogovi Province, Mongolia, January to April 2011. Western Pacific Surveillance and Response Journal, 2012, 3(4):53-58. doi:10.5365/wpsar.2012.3.3.007

14. Datta $S$ et al. Pertussis outbreak in Papua New Guinea: the challenges of response in a remote geo-topographical setting. Western Pacific Surveillance and Response Journal, 2012, 3(4):3-6. doi:10.5365/wpsar.2012.3.3.008

15. Battsendiin $M$ et al. An outbreak of syphilis in Darkhan-Uul Province, Mongolia, January to March 2012. Western Pacific Surveillance and Response Journal, 2012, 3(4):48-52. doi: 10.5365/wpsar.2012.3.4.003

16. Zhang $\mathrm{T}$ et al. Investigation of an outbreak of cutaneous anthrax in Banlu village, Lianyungang, China, 2012. Western Pacific Surveillance and Response Journal, 2012, 3(4):12-15. doi:10.5365/wpsar.2012.3.4.005 